\title{
Somatic symptoms beyond those generally associated with a whiplash injury are increased in self-reported chronic whiplash. A population- based cross sectional study: the Hordaland Health Study (HUSK)
}

Solbjørg Makalani Myrtveit ${ }^{1,2}$, Jens Christoffer Skogen ${ }^{3}$, Hanne Gro Wenzel ${ }^{4}$ and Arnstein Mykletun ${ }^{2,3,5^{*}}$

\begin{abstract}
Background: Chronic whiplash leads to considerable patient suffering and substantial societal costs. There are two competing hypothesis on the etiology of chronic whiplash. The traditional organic hypothesis considers chronic whiplash and related symptoms a result of a specific injury. In opposition is the hypothesis that chronic whiplash is a functional somatic syndrome, and related symptoms a result of society-induced expectations and amplification of symptoms. According to both hypotheses, patients reporting chronic whiplash are expected to have more neck pain, headache and symptoms of anxiety and depression than the general population. Increased prevalence of somatic symptoms beyond those directly related to a whiplash neck injury is less investigated. The aim of this study was to test an implication derived from the functional hypothesis: Is the prevalence of somatic symptoms as seen in somatization disorder, beyond symptoms related to a whiplash neck injury, increased in individuals self-reporting chronic whiplash? We further aimed to explore recall bias by comparing the symptom profile displayed by individuals self-reporting chronic whiplash to that among those self-reporting a non-functional injury: fractures of the hand or wrist. We explored symptom load, etiologic origin could not be investigated in this study.

Methods: Data from the Norwegian population-based "Hordaland Health Study" (HUSK, 1997-99); N=13,986 was employed. Chronic whiplash was self-reported by 403 individuals and fractures by 1,746. Somatization tendency was measured using a list of 17 somatic symptoms arising from different body parts and organ systems, derived from the research criteria for somatization disorder (ICD-10, F45).
\end{abstract}

Results: Chronic whiplash was associated with an increased level of all 17 somatic symptoms investigated $(p<0.05)$. The association was moderately strong (group difference of 0.60 standard deviation), only partly accounted for by confounding. For self-reported fractures symptoms were only slightly elevated. Recent whiplash was more commonly reported than whiplash-injury a long time ago, and the association of interest weakly increased with time since whiplash $(r=0.016, p=0.032)$.

Conclusions: The increased prevalence of somatic symptoms beyond symptoms expected according to the organic injury model for chronic whiplash, challenges the standard injury model for whiplash, and is indicative evidence of chronic whiplash being a functional somatic syndrome.

Keywords: Chronic whiplash, Somatic symptoms, Somatization, Functional somatic syndrome, Biopsychosocial

\footnotetext{
* Correspondence: arnstein.mykletun@iuh.uib.no

${ }^{2}$ Division of Mental Health, Department of Public Mental Health, Norwegian

Institute of Public Health, Bergen, Norway

${ }^{3}$ Research Unit on Mental Health Epidemiology, Department of Health

Promotion and Development, Faculty of Psychology, UoB, Bergen, Norway

Full list of author information is available at the end of the article
} 


\section{Background}

The term "whiplash" was first introduced in 1928 [1], describing the lash-like effect caused by sudden accelerationdeceleration forces acting on neck and upper trunk, mainly following a rear impact [2]. A whiplash injury is generally considered an uncomplicated soft tissue injury of the neck, fractures and dislocations are excluded [2].

In the acute phase after a whiplash injury, lasting up to four weeks, the most common symptoms are pain and stiffness of the neck and headache $[3,4]$. The condition is usually benign and the majority of patients rapidly recover [4-6]. After 3 months, however, recovery seems to level off and despite examinations revealing no neck changes, a substantial amount of patients remains symptomatic $[7,8]$. Estimates on the transition from acute whiplash to chronic whiplash, defined as symptoms still seen after 6 months $[6,9]$, vary greatly, between $6 \%$ and $50 \%[2,5,10]$.

Chronic whiplash represents a considerable burden to the society, both health care systems, insurance systems and compensation systems [11]. Patients with chronic whiplash report the disorder to negatively affect their ability to work and reduce their quality of life $[2,12]$. They also report more symptoms of anxiety and depression than the general population $[13,14]$, and more somatic symptoms like head and neck pain [15-19]. Sufferers of chronic whiplash also report elevated levels of somatic symptoms from body areas not affected by a neck trauma; like gastrointestinal symptoms, palpitations, shortness of breath and sleep disturbances [15,18,20-22].

Some consider chronic whiplash an organic disorder with chronic pain due to injuries in the neck [23], which is what we call the organic hypothesis. There is converging evidence available indicating prevalence of peripheral lesions in some individuals after a whiplash injury [24], but these lesions might not be prerequisite for clinical features seen among sufferers of chronic whiplash [25]. Also, the increased load of diffuse somatic symptoms is difficult to explain if chronic whiplash is considered a mere result of a neck injury. So, regardless if some symptoms are the result of physical injury, it is important to consider other processes than the pure organic that might initiate and maintain symptoms [25].

This has inspired the claim that chronic whiplash is better understood as one of many functional somatic syndromes [21,26,27]. Functional somatic syndromes are characterized by medically unexplained symptoms and suffering $[26,28]$. The symptoms reported by individuals with functional somatic syndromes are prevalent in healthy populations $[29,30]$ and characterized by diffuse and non-specific symptoms emerging from different organs and body parts [26,28,30-32]. Furthermore, the symptoms of functional somatic syndromes are very similar to somatization disorder, and the two conditions are thought to be closely related $[26,33,34]$.
There are alternative models and explanations for increased symptoms beyond those expected according to the organic model for whiplash. One alternative explanation can be called the recall bias hypothesis. This hypothesis suggests that the generally increased symptom load in self-reported whiplash is a memory, response style or attention bias seen in some individuals, producing positive responses to questions regarding both past injuries and recent symptoms. By way of anxiety, personality, the belief that one is sick, negative expectations about the future course of the disease and stressful events, diffuse symptoms present in the general population might by some individuals be perceived as more noxious and troublesome [26]. Also, individuals experiencing increased symptom load are more likely to think about what could cause their symptoms - and will therefore to a greater extent recall and report injuries of all sorts. This hypothesis can, however, be tested by exploring whether symptoms as seen in somatization disorder are elevated in a self-reported past non-functional disorder, i.e. fractures of hand or wrist.

The purpose of this study was to investigate whether self-reported whiplash injuries are associated with increased prevalence of a broad range of somatic symptoms not readily related to a neck injury. To explore if our finding is merely a result of recall bias, we also explored if the same somatic symptoms are equally increased in self-reported past fractures of hand or wrist. Finally, we aimed to examine if the proportion of the population self-reporting whiplash diminishes with time, and how the symptom burden changes with time since the whiplash injury.

\section{Methods}

\section{Study population}

Data from the "Hordaland Health Study" (HUSK) carried out in Hordaland County in Western Norway between 1997 and 1999 were used. This joint epidemiological research project was conducted in cooperation between the National Norwegian Health Screening Services, the University of Bergen and local health services. The base population included 29,400 individuals born between 1953 and 1957 and aged 40-46 years upon participation. Of these, 18,565 (8,585 men and 9,980 women) accepted the invitation, filled in the questionnaires and attended clinical examinations including measures of blood pressure, height, weight, waist- and hip circumference. This resulted in a general participation rate of $63 \%$ (57\% for men and $70 \%$ for women). For the purpose of the present study, we were interested in individuals reporting whiplash or no whiplash, a fractured hand/wrist or no fractured hand/wrist, and their profile of somatic symptoms. Excluding everyone not answering the questions related to whiplash, a fractured hand/wrist, questions on 
somatic symptoms and questions on covariates potentially associated with both exposure and outcome, left us with a study population of 13,986 individuals ( $75 \%$ of the HUSK participants; 2,756 excluded due to missing data on outcome and exposure and 1,823 excluded due to missing data on covariates).

\section{Exposure - whiplash}

As in previous studies [13,35], self-reported incident whiplash was assessed using the question "Have you ever experienced whiplash?", together with a follow-up question on how old the person was at the time of the injury. In correspondence with previous work [21], we defined our group of chronic whiplash sufferers as individuals having experienced the trauma no sooner than one year prior to the survey and reporting neck pain for at least three consecutive months during the last year. Individuals possibly still in their acute phase of the disorder (having experienced whiplash less than one year ago, $\mathrm{N}=11$ ) and individuals reporting a whiplash trauma but not having developed chronic neck pain $(\mathrm{N}=33)$ were excluded. This resulted in a group of $\mathrm{N}=403$ (2.9\%) potential sufferers of chronic whiplash. These individuals were compared to the rest of the HUSK participants (no chronic whiplash, $\mathrm{N}=13,583$ ) in our analyses.

\section{Comparison exposure - fractured hand/wrist}

In the same section and wording as for whiplash, participants were also asked whether they have ever fractured their hand or wrist. There was no missing for this item and $\mathrm{N}=1,746(12.5 \%)$ reported a past fracture of the hand or wrist.

\section{Outcome - somatic symptoms}

The frequencies of common somatic symptoms arising from different body parts and organ systems were investigated. For this, a list of 17 somatic symptoms (abdominal pain, nausea, bloating, tongue plaque, regurgitation, frequent defecation, discomfort in genital region, skin discoloring, joint/muscle pain, dizziness, tiredness, paresthesia in extremities, burning eyes, headache, shortness of breath, chest pain and problems with urination) was used. The list contains 13 items from the ICD-10 research criteria for somatization disorder (F45) [33] and 4 other symptoms related to somatization and functional somatic syndromes $[26,28,36]$. It has previously been used when exploring somatization $[37,38]$.

The participants were asked to indicate the frequency of which they experience each symptom by ticking off "almost never", "rarely", "sometimes", "often" or "almost always". The two latter possibilities were truncated to one, yielding a symptom load ranging from $1-4$. The mean frequency of complaints was calculated across symptoms for each individual. As in previous studies
$[37,38]$, this mean score was used as an indication of somatization tendency.

\section{Covariates}

Functional somatic syndromes, somatic symptoms and self-reported whiplash are related to a whole range of socio-demographic and health related factors $[26,27,34,36,39-41]$. We have therefore adjusted the association for the following factors:

Gender was registered, as was marital status, grouped into "not married", "married", "separated", "divorced" or "widow/widower". Socioeconomic status was assessed trough questions on benefit receipt and education. Participants were asked if they, at the time of participation, received any social aid or pension (Table 1). In relation to education, participants were grouped as having completed "compulsory only", "high school" or "university". The 133 not answering this question were set to "compulsory only".

As somatic diagnoses can affect the symptom profile, we are investigating the number of somatic illnesses each individual was suffering from at participation time, or had suffered from earlier. The number of diagnoses was recorded as participants ticked off the following: heart infarction, angina pectoris, stroke, asthma, diabetes or multiple sclerosis. The responses from 18 participants reporting 3 or more somatic diagnosis were truncated to 3 .

Anxiety and depression were measured using the "Hospital Anxiety and Depression Scale" (HADS) [42]. HADS is a widely used self-report questionnaire considered reliable for patients in psychiatric and nonpsychiatric settings, and for the general population [43-45]. The questionnaire consists of 14 readily understandable questions on symptoms, seven for depression (HADS-D) and seven for anxiety (HADS-A). Somatic symptoms commonly seen in anxiety and depression are excluded, making the scale useful in populations with somatic illness and symptoms. Each item has four alternative responses ranging from symptom not present (0) to maximum reported level of symptom (3), giving a sum score range from 0 to 21 for both subscales. In accordance with previous studies, a valid rating of depression and anxiety was defined as at least 5 completed items on each sub-scale (HADS-S and HADS-D) $[45,46]$, and the recommended cut-off score of $\geq 8$ was used in the descriptive table [43-45].

Health-related behavior was evaluated in line with previous studies $[47,48]$. The participants were asked "Do you smoke cigarettes, cigars and/or pipe daily" and grouped as smokers or non-smokers. Physical activity was evaluated by asking how often and for how long the participants engaged in both light and intense leisuretime physical activity. Light activity was defined as 
Table 1 Summary of the variables included in the analysis, and differences between individuals reporting chronic whiplash and individuals not reporting chronic whiplash

\begin{tabular}{|c|c|c|c|c|}
\hline Covariates & Chronic whiplash $N=403$ & No chronic whiplash $\mathrm{N}=13,583$ & P-value (Chi-square test) & All $\mathrm{N}=13,986$ \\
\hline Female & $58.3 \%$ & $53.9 \%$ & 0.079 & $54.0 \%$ \\
\hline Anxiety & $24.1 \%$ & $17.6 \%$ & 0.001 & $17.8 \%$ \\
\hline Depression & $14.6 \%$ & $9.6 \%$ & 0.001 & $9.8 \%$ \\
\hline Sleep quality & & & $<0.001$ & \\
\hline Good & $37.0 \%$ & $42.6 \%$ & & $42.4 \%$ \\
\hline Bad & $17.9 \%$ & $11.1 \%$ & & $11.4 \%$ \\
\hline Not asked & $45.2 \%$ & $46.3 \%$ & & $46.3 \%$ \\
\hline Education & & & 0.119 & \\
\hline Compulsory only & $13.7 \%$ & $17.5 \%$ & & $17.4 \%$ \\
\hline High School & $46.9 \%$ & $45.7 \%$ & & $45.7 \%$ \\
\hline University & $39.5 \%$ & $36.8 \%$ & & $36.9 \%$ \\
\hline Benefit recipiency & $28.3 \%$ & $13.0 \%$ & $<0.001$ & $13.4 \%$ \\
\hline Sickness benefit & $10.9 \%$ & $4.6 \%$ & & $4.7 \%$ \\
\hline Occupational habilitation & $3.5 \%$ & $1.1 \%$ & & $1.1 \%$ \\
\hline Disability pension & $11.9 \%$ & $3.3 \%$ & & $3.6 \%$ \\
\hline Social benefit & $1.5 \%$ & $0.5 \%$ & & $0.6 \%$ \\
\hline Unemployment benefit & $2.5 \%$ & $1.6 \%$ & & $1.7 \%$ \\
\hline Dependents' pension & $0.5 \%$ & $0.7 \%$ & & $0.7 \%$ \\
\hline Other & $2.7 \%$ & $2.6 \%$ & & $2.6 \%$ \\
\hline Physical activity & & & 0.369 & \\
\hline None & $17.4 \%$ & $15.5 \%$ & & $15.6 \%$ \\
\hline Easy & $38.7 \%$ & $41.9 \%$ & & $41.8 \%$ \\
\hline Heavy & $43.9 \%$ & $42.5 \%$ & & $42.6 \%$ \\
\hline Alcohol consumption & & & 0.838 & \\
\hline No consumption & $27.1 \%$ & $28.3 \%$ & & $28.3 \%$ \\
\hline Moderate consumption & $67.5 \%$ & $66.1 \%$ & & $66.1 \%$ \\
\hline Heavy consumption & $5.5 \%$ & $5.6 \%$ & & $5.6 \%$ \\
\hline Daily smoking & $37.5 \%$ & $35.5 \%$ & 0.416 & $35.6 \%$ \\
\hline Somatic diagnoses $>0$ & $11.9 \%$ & $8.1 \%$ & 0.006 & $8.2 \%$ \\
\hline Marital status & & & 0.090 & \\
\hline Not married & $11.2 \%$ & $12.7 \%$ & & $12.6 \%$ \\
\hline Married & $71.5 \%$ & $74.6 \%$ & & $74.5 \%$ \\
\hline Separated & $3.0 \%$ & $2.4 \%$ & & $2.4 \%$ \\
\hline Divorced & $13.7 \%$ & $9.7 \%$ & & $9.8 \%$ \\
\hline Widow/Widower & $0.7 \%$ & $0.7 \%$ & & $0.7 \%$ \\
\hline Mean somatisation $>2$ & $43.2 \%$ & $21.4 \%$ & $<0.001$ & $22.1 \%$ \\
\hline
\end{tabular}

activity that did not lead to being sweaty or out of breath, while intense activity was activity that did result in sweating or breathlessness. Individuals were then divided into groups performing "no physical activity", "moderate physical activity" and "heavy physical activity". Amount of alcohol consumption was assessed using two questions: "Do you abstain from alcohol?" and "What is your normal consumption of alcoholic beverages within
14 days?". Based on this, using a cut-off value of 15 units, participants were grouped to have "no consumption", "moderate consumption", or "high consumption".

After the first questionnaire and the clinical examination, a second questionnaire was distributed to a random subsample and completed by 8,896 individuals [49]. This questionnaire contained a question on sleep which was included as a covariate in this subsample. Sleep was 
evaluated by the question "How often do you experience sleep difficulties", with tick-off possibilities "never/a few times a year", "once or twice a month", "once a week" and "more than once a week". Participants answering one of the two first were considered as having good sleep, participants answering one of the two latter were considered as having bad sleep.

\section{Statistical procedure}

To enable a comparison between the whiplash-group and the no whiplash-group in relation to somatic symptom profiles, the reported frequency of each symptom was standardized (z-scored) with a mean of 0 and a standard deviation of 1 [50]. This standardization enables a straightforward interpretation of reported frequency across the different somatic symptoms. Independent $\mathrm{t}$-tests were then employed to each of the standardized symptoms and the standardized mean frequency of the reported symptoms (somatization).

In order to adjust for covariates, a multiple linear regression model was employed. Each covariate was adjusted for separately, but all regressions included gender. A fully adjusted model was computed. Also a separate regression analysis was conducted, adjusting each symptom for all covariates. These analyses were then repeated for individual self-reporting a past fracture of the hand or wrist.

To investigate the unadjusted association between the standardized mean frequency of reported symptoms and time since whiplash-accident, a linear regression model was employed.

STATA/SE 10 [51] for Mac was used for all analyses.
Ethics

All the participants in this study gave their written consent upon inclusion. The HUSK study was approved by the Regional Committee for Medical Research Ethics of Western Norway and the Norwegian Data Inspectorate.

\section{Results}

In the analyzed sample ( $\mathrm{N}=13,986), \mathrm{N}=403(2.9 \%)$ individuals reported chronic whiplash. The individuals in the whiplash group reported more symptoms of anxiety and depression and were more likely to be benefit recipients than those in the comparison group. They also reported a higher number of somatic diagnoses and worse sleep (Table 1).

Compared to the group of individuals reporting no whiplash, the mean reported frequency of somatic symptoms in the whiplash group was $0.60 \mathrm{SD}$ higher. When adjusting for potential covariates, the mean difference in symptom reporting was attenuated to $0.41 \mathrm{SD}$ in the fully adjusted model (Table 2). The variables which separately attenuated the mean difference the most were "benefit receipt", "anxiety" and "depression".

All examined symptoms were elevated in individuals with chronic whiplash compared to those with no chronic whiplash (Figure 1). "Headache" and "dizziness" showed the largest difference in frequency (mean difference 0.50 and $0.49 \mathrm{SD}$ ). Also "joint/muscle pain", "tiredness", "paresthesia in extremities" and "nausea" had a mean difference at levels of $0.40 \mathrm{SD}$ or higher. There was a mean difference between 0.20 to 0.40 for the symptoms "shortness of breath", "chest pain", "abdominal pain", "bloating", "frequent defecation", "regurgitation" and

Table 2 Mean difference of reported somatic symptoms compared between individuals reporting chronic whiplash and individuals not reporting chronic whiplash, and between individuals reporting a past fractured hand or wrist and no previous fractured hand or wrist

\begin{tabular}{|c|c|c|c|c|c|}
\hline \multicolumn{3}{|c|}{ Chronic whiplash compared to no chronic whiplash } & \multicolumn{3}{|c|}{ Fractured hand or wrist compared to no fractured hand or wrist } \\
\hline Variables & B & $(\mathrm{Cl})$ & Variables & B & $(\mathrm{Cl})$ \\
\hline No adjustments & 0.60 & $0.50-0.69$ & No adjustments & 0.07 & $0.02-0.12$ \\
\hline Gender & 0.58 & $0.48-0.68$ & Gender & 0.12 & $0.07-0.17$ \\
\hline Education & 0.59 & $0.49-0.69$ & Education & 0.13 & $0.08-0.18$ \\
\hline Benefit receipt & 0.49 & $0.40-0.59$ & Benefit receipt & 0.10 & $0.05-0.15$ \\
\hline Anxiety $^{a}$ & 0.46 & $0.38-0.55$ & Anxiety $^{a}$ & 0.09 & $0.05-0.14$ \\
\hline Depression $^{\mathrm{a}}$ & 0.51 & $0.42-0.60$ & Depression $^{a}$ & 0.11 & $0.06-0.15$ \\
\hline Somatic diagnosis & 0.56 & $0.46-0.66$ & Somatic diagnosis & 0.11 & $0.07-0.16$ \\
\hline Physical activity & 0.58 & $0.48-0.68$ & Physical activity & 0.13 & $0.08-0.18$ \\
\hline Consumption of alcohol & 0.58 & $0.48-0.68$ & Consumption of alcohol & 0.12 & $0.07-0.17$ \\
\hline Daily smoking & 0.58 & $0.48-0.67$ & Daily smoking & 0.12 & $0.07-0.17$ \\
\hline Marital status & 0.57 & $0.47-0.67$ & Marital status & 0.12 & $0.07-0.17$ \\
\hline Fully adjusted & 0.41 & $0.33-0.49$ & Fully adjusted & 0.08 & $0.04-0.12$ \\
\hline
\end{tabular}

Adjustments for covariates; separately and fully adjusted.

${ }^{a}$ Anxiety and depression entered as a continuous variable. 
"burning eyes". The symptoms "tongue plaque", "skin discoloring", "discomfort in genital region" and "urination problems" had a mean difference between 0.10 and 0.20 SD. Fully adjusted, all individual symptoms remained statistically significant apart from "urination problems" $(\mathrm{p}=0.224)$ and "discomfort in genital region" $(\mathrm{p}=0.159)$ (Table 3).

The mean time since whiplash injury was 10.8 years (range 1 to 45 ), and the proportion reporting chronic whiplash declined strongly with increasing time since the whiplash injury (Figure 2). The association between chronic whiplash and somatic symptoms was stronger amongst those reporting having experienced a whiplash injury a long time ago, than amongst those reporting a more resent injury. The tendency was rather weak and borderline significant (within whiplash group, correlation $\mathrm{r}=0.016 \quad(\mathrm{p}=0.032)$ between time since whiplash and somatic symptoms (Figure 2)).

A fracture of the hand or wrist was self-reported by $\mathrm{n}=1,756$ individuals (12.5\%). The mean difference of symptom reporting between those reporting fracture and those reporting no fracture was 0.07 SD. Adjusting for possible confounders changed the mean difference to 0.08 SD. Only six of the somatic symptoms investigated (regurgitation, frequent defecation, joint/muscle pain, burning eyes, chest pain and shortness of breath) showed a significant difference between those reporting a fracture and those reporting no fracture.

\section{Discussion}

\section{Main findings}

Self-report of chronic whiplash was associated with increased frequency of all somatic symptoms examined. Adjusting for potential confounding variables only partly accounted for this difference. A memory or response style bias only cannot explain all of the increased symptom reporting: self-reporting fractures of the wrist or hand was associated with only a few somatic symptoms and only weakly so.

Finally, a declining number of self-reported whiplash injuries were found with increasing time since the accident. Older whiplash injuries were associated with more somatic symptoms reported at participation in HUSK.

\section{Strengths and limitations}

The main strength of this study is the population-based design enabling a comparison between a group of chronic whiplash sufferers and a healthy population. Clinical data would not be appropriate for a study like this due to selection bias. Individuals with a heavy symptom load would to a greater extent seek medical help after a whiplash injury than others, resulting in an exaggerated symptom reporting in the chronic whiplash group. Using a population-based design, we were able to compare all individuals reporting a whiplash injury and neck pain, including individuals not in contact with health services.

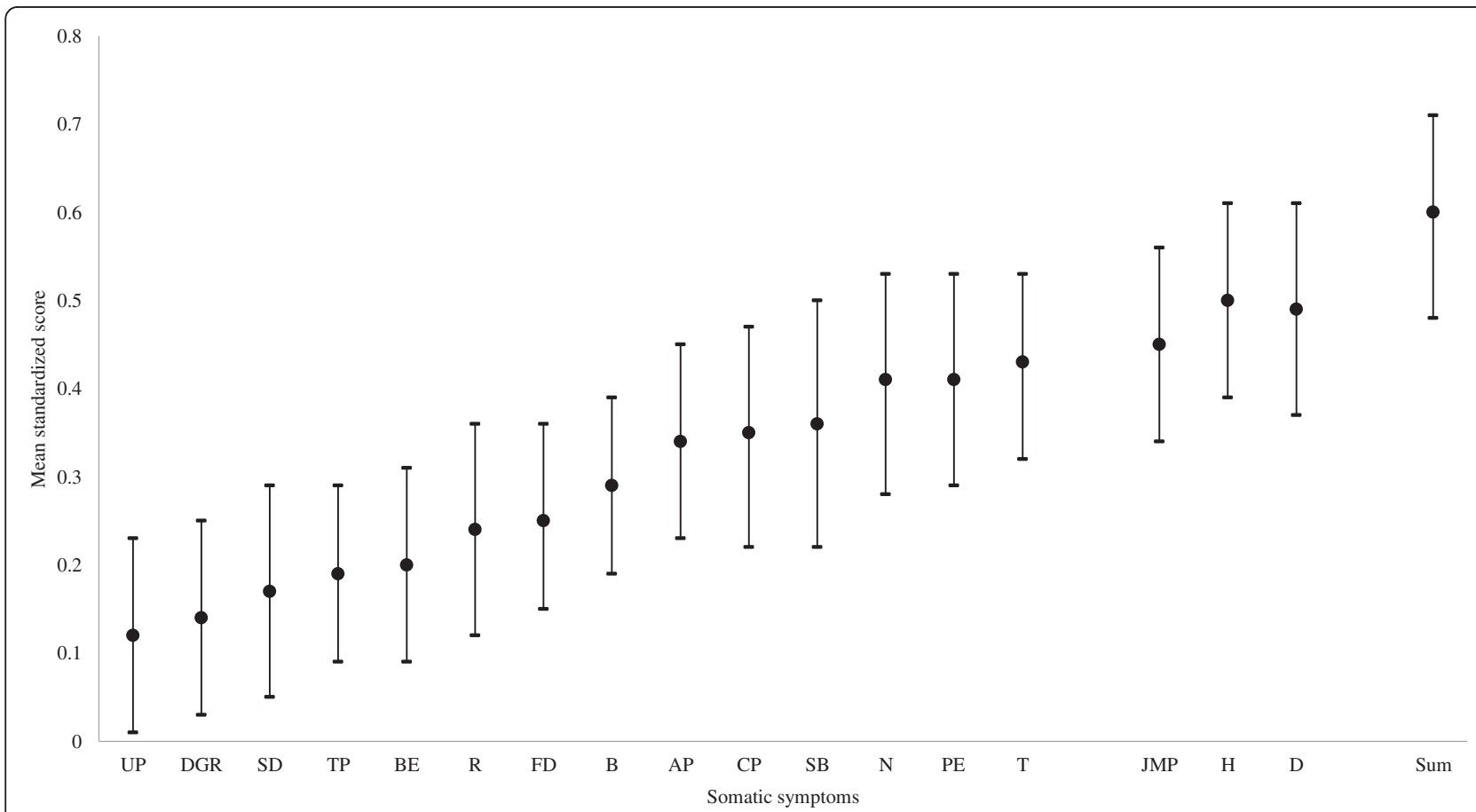

Figure 1 Mean difference in the association between those reporting chronic whiplash and somatic symptoms compared to those not reporting chronic whiplash. 
Table 3 Mean difference of reported frequency of 17 somatic symptoms compared between individuals reporting chronic whiplash and individuals not reporting chronic whiplash and individuals reporting a past fractured hand or wrist and no past fractured hand or wrist, unadjusted, adjusted for gender and fully adjusted

\begin{tabular}{|c|c|c|c|c|c|c|}
\hline \multirow[b]{2}{*}{ Somatic symptoms } & \multicolumn{3}{|c|}{ Chronic whiplash compared to no chronic whiplash } & \multicolumn{3}{|c|}{ Fractured wrist compared to no fractured hand/wrist } \\
\hline & $\begin{array}{l}\text { Unadjusted } \\
\text { B (CI) }\end{array}$ & $\begin{array}{l}\text { Adjusted for gender } \\
\text { B (CI) }\end{array}$ & $\begin{array}{l}\text { Fully adjusted* } \\
\text { B (CI) }\end{array}$ & $\begin{array}{l}\text { Unadjusted } \\
\text { B (CI) }\end{array}$ & $\begin{array}{l}\text { Adjusted for gender } \\
\text { B (CI) }\end{array}$ & $\begin{array}{c}\text { Fully adjusted* } \\
\text { B (CI) }\end{array}$ \\
\hline Headache $(\mathrm{H})$ & $0.50(0.40-0.60)$ & $0.48(0.38-0.57)$ & $0.40(0.31-0.49)$ & $-0.01(-0.06-0.04)$ & $0.05(0.01-0.10)$ & $0.04(-0.00-0.09)$ \\
\hline Dizziness (D) & $0.49(0.39-0.59)$ & $0.47(0.38-0.57)$ & $0.36(0.26-0.45)$ & $-0.01(-0.06-0.04)$ & $0.04(-0.01-0.09)$ & $0.01(-0.04-0.06)$ \\
\hline Joint/muscle pain (JMP) & $0.45(0.35-0.55)$ & $0.44(0.34-0.53)$ & $0.32(0.23-0.42)$ & $0.07(0.02-0.12)$ & $0.11(0.06-0.16)$ & $0.08(0.03-0.13)$ \\
\hline Abdominal pain (AP) & $0.34(0.24-0.44)$ & $0.33(0.23-0.43)$ & $0.24(0.14-0.33)$ & $0.04(-0.01-0.09)$ & $0.08(0.03-0.13)$ & $0.05(0.00-0.10)$ \\
\hline Nausea (N) & $0.41(0.31-0.51)$ & $0.39(0.30-0.49)$ & $0.30(0.20-0.39)$ & $0.00(-0.05-0.05)$ & $0.04(-0.01-0.09)$ & $0.02(-0.03-0.06)$ \\
\hline Bloating (B) & $0.29(0.19-0.39)$ & $0.27(0.18-0.37)$ & $0.19(0.10-0.29)$ & $0.02(-0.03-0.07)$ & $0.08(0.03-0.13)$ & $0.06(0.01-0.11)$ \\
\hline Tongue plaque (TP) & $0.19(0.09-0.28)$ & $0.18(0.08-0.28)$ & $0.10(0.00-0.20)$ & $0.05(-0.00-0.10)$ & $0.07(0.01-0.12)$ & $0.04(-0.01-0.09)$ \\
\hline Regurgitation (R) & $0.24(0.14-0.34)$ & $0.24(0.14-0.34)$ & $0.17(0.08-0.27)$ & $0.07(0.02-0.12)$ & $0.06(0.01-0.11)$ & $0.04(0.01-0.09)$ \\
\hline Frequent defecation (FD) & $0.25(0.16-0.35)$ & $0.26(0.16-0.36)$ & $0.18(0.08-0.27)$ & $0.10(0.05-0.15)$ & $0.07(0.02-0.12)$ & $0.05(-0.00-0.10)$ \\
\hline $\begin{array}{l}\text { Discomfort in genital } \\
\text { region (DGR) }\end{array}$ & $0.14(0.04-0.24)$ & $0.13(0.03-0.23)$ & $0.07(-0.03-0.17)$ & $-0.02(-0.07-0.03)$ & $0.02(-0.03-0.07)$ & $0.01(-0.04-0.06)$ \\
\hline Skin discoloring (SD) & $0.17(0.07-0.27)$ & $0.17(0.07-0.27)$ & $0.11(0.01-0.21)$ & $0.04(-0.01-0.09)$ & $0.04(-0.01-0.09)$ & $0.02(-0.03-0.07)$ \\
\hline Tiredness ( $T$ ) & $0.43(0.33-0.52)$ & $0.41(0.31-0.51)$ & $0.25(0.16-0.33)$ & $0.01(-0.04-0.06)$ & $0.05(0.01-0.10)$ & $0.01(-0.03-0.06)$ \\
\hline $\begin{array}{l}\text { Paresthesia in extremities } \\
\text { (PE) }\end{array}$ & $0.41(0.31-0.51)$ & $0.40(0.30-0.50)$ & $0.30(0.20-0.39)$ & $0.04(-0.01-0.09)$ & $0.06(0.01-0.11)$ & $0.03(-0.02-0.08)$ \\
\hline Burning eyes (BE) & $0.20(0.10-0.30)$ & $0.19(0.09-0.29)$ & $0.12(0.02-0.22)$ & $0.05(0.00-0.10)$ & $0.08(0.03-0.13)$ & $0.07(0.02-0.11)$ \\
\hline Shortness of breath (SB) & $0.36(0.26-0.46)$ & $0.36(0.26-0.46)$ & $0.25(0.15-0.34)$ & $0.07(0.02-0.12)$ & $0.08(0.03-0.13)$ & $0.05(0.00-0.09)$ \\
\hline Chest pain (CP) & $0.35(0.25-0.45)$ & $0.35(0.26-0.45)$ & $0.26(0.17-0.36)$ & $0.12(0.07-0.17)$ & $0.11(0.06-0.16)$ & $0.08(0.03-0.13)$ \\
\hline Urination problems (UP) & $0.12(0.02-0.22)$ & $0.11(0.01-0.21)$ & $0.06(-0.04-0.16)$ & $0.03(-0.02-0.08)$ & $0.06(0.01-011)$ & $0.05(0.00-0.10)$ \\
\hline
\end{tabular}

${ }^{*}$ Adjusted for gender, anxiety, depression, education, benefit receipt, physical activity, marital status, consumption of alcohol, daily smoking and somatic diagnosis.

The large number of participants and the relatively high participation rate should also be noted as advantages. Furthermore, the dataset contains information on many co-variables, making adjustments for multiple confounders possible. The richness of variables also enabled us to explore if the recall bias hypothesis by comparing our results to that of self-reported fractures.

Both participants in the health study and the staff collecting the data were blinded to the specific hypothesis of this study. Also, the study was conducted in no relation to any litigation, compensation or insurance process. This is important, as such processes have been found to lead to increased symptom reporting and delayed recovery $[52,53]$.

The study also has some notable limitations. Firstly, the study is cross-sectional, making it impossible to conclude on causal inference. For instance, somatic symptoms and symptoms of anxiety and depression might have been present before the accident. Increased preinjury levels of symptoms of anxiety and depression have been found [35], and reporting low pre-injury physical and mental health predicts whiplash [54].

All data used are self-reported with no objective confirmation. This applies both to self-report of whiplash and fracture of hand or wrist. We do not know if chronic whiplash developed after the whiplash accident: Some individuals in our chronic whiplash group might be recovered from the accident but reporting neck pain with an etiology different from whiplash.

Information based on self-report make the study design vulnerable to possible recall bias; hence increased tendency in some individuals for whatever reason to remember both past injuries and recent symptoms. We aimed to explore the relevance of this bias by repeating all analyses for fractures of the hand or wrist. As symptoms were only slightly increased in individuals selfreporting fractures, we conclude the recall bias problem might be relevant, but cannot entirely explain the increased symptom report in chronic whiplash.

Previous studies have used self-reported data and similar methods of classification when investigating chronic whiplash [13,21]. A recent study found self-reported whiplash to strongly predict a subsequent allowance of disability benefits [35], indicating clinical relevance of self-reported whiplash, whether it is picking up true whiplash sufferers or not. The lack of a medical confirmation is truly a limitation if to be regarded a study of true whiplash victims. We do believe the overlap between 


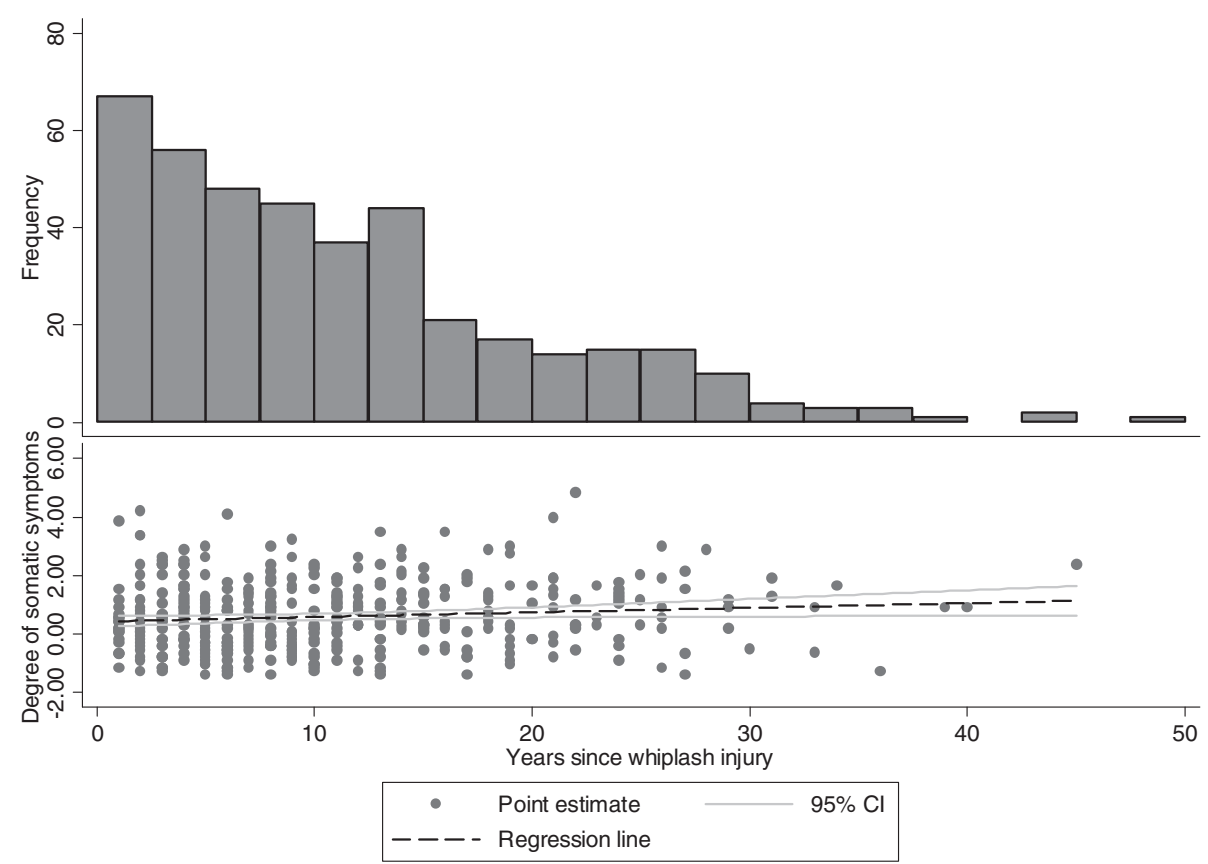

Figure 2 Somatic symptoms, frequency of participants reporting whiplash and time since accident.

self-reported whiplash and sufferers of whiplash injuries who could be clinically verified to be far from perfect, including both false negatives and false positives (i.e. selfdiagnosed whiplash). We do, however, also believe that the group self-reporting whiplash is clinically relevant with the highly increased prevalence of somatic symptoms and increased risk of future disability benefits.

Somatic symptoms are also self-reported. The questions related to somatic symptoms were not linked to whiplash in the questionnaire used in HUSK. This could reduce the risk of attribution and symptom accentuating in relation to data collection.

Participants report their symptoms unrelated to any medical condition. We do not know whether the particular participant has an organic explanation for the reported symptoms. Though a broad symptom profile can be difficult to explain within chronic whiplash [55], some of the symptoms seen might have an organic etiology related to the accident. Our study design, did not, however, allow for evaluation of whether or not each symptom was organic in origin.

Also, other somatic diagnoses could lead to increased load of somatic symptoms. Participants were asked if they suffered from heart infarction, angina pectoris, stroke, asthma, diabetes or multiple sclerosis. The association between somatic symptoms and chronic whiplash was adjusted for these comorbid diagnoses. The mean difference in symptom reporting was changed by only $3.4 \%$ (from 0.58 to $0.56 \mathrm{SD}$ ) when adjusting for these comorbid diagnoses. Whether more of the association could have been explained by inclusion of somatic diagnoses beyond those available in this study remains an open question.

Another limitation is the narrow age span. The basepopulation for the Hordaland Health Study was 29,400 individuals living in Hordaland County, born between 1953 and 1957. Some researchers find age to hold no prognostic importance after a whiplash accident [56], while others claim older age to increase the risk of poor recovery [57]. A review from 2008 claims conflicting results [58]. Consequently, we cannot exclude the possibility that the narrow age range of our study limits the generalizability of findings.

\section{Interpretation of findings}

Our findings of increased reporting of diffuse symptoms from all body parts among chronic whiplash sufferers and the positive linear association between time since whiplash injury and frequency of somatic symptoms are hard to explain within the organic model. The findings are more compatible with, and indicative evidence of, a functional element within chronic whiplash. However, other explanations may also be relevant.

In line with previous studies [4,7,16,17,19,59-61], the most frequent symptoms amongst chronic whiplash sufferers were headache, dizziness and neck pain/jointmuscle pain. Somatic symptoms beyond headache, dizziness and joint/muscle pain have not previously been as 
thoroughly explored in the literature. Some studies have found increased levels of gastrointestinal symptoms, palpitations, shortness of breath and sleep disturbances [15,21], but to the best of our knowledge, this is the first study showing that the entire range of somatic symptoms included in the ICD-10 criteria for somatization disorder are increased in individuals self-reporting whiplash.

Different theories aim to explain increased symptom reporting in chronic whiplash: For instance, changes in zygapophysial joints seem to cause neck pain and headache in some individuals after whiplash injuries $[24,55,62,63]$. In contrast, it is claimed that no MRI changes can be found after whiplash injuries, not for acute [64], nor chronic cases [7,65-67].

Stress system responses including catecholaminergic systems, serotonin systems and the hypothalamicpituitary-adrenocortical systems also appear capable of producing hyperalgesia and allodynia $[25,68]$.

As in other chronic pain conditions, sensitization might be of importance $[25,69]$. The sensitization model explains pain as having a physical cause related to changes in the nervous system [70]: After repetitive activation of nociceptors, specific neurons within the spinal cord become sensitized. Also, new connections are made between neurons and inhibitory neurons die. Following this, non-nociceptive stimuli from the periphery may now be misinterpreted as pain. The model further stresses that psychological, behavioral and social problems are related to the existence and persistence of sensitization.

Headache, dizziness and neck pain/joint-muscle pain arise from the neck- and head-area and are therefore the symptoms most easily explained by a whiplash neck injury. As these symptoms are important among individuals suffering from chronic whiplash, we included them in our study. But as they in relation to chronic whiplash cannot be regarded as unexplained diffuse somatic symptoms, they are set aside from the other symptoms in tables/figures.

In our study we cannot explore the cause or origin of symptoms; we solely investigate the symptom load in chronic whiplash. Also, regardless of whether some symptoms are caused by physical injury, other processes might also be of great importance in the development and maintenance of chronic suffering after a whiplash accident.

For instance, theories on symptom amplification and re-attribution $[26,40]$ are useful in explaining our findings. We will consider neck pain as an example. Neck pain is common in the general population, and an individual experiencing a whiplash injury might have had neck pain before the incident. After the accident, however, he/she becomes more aware of the neck pain, and considers the neck pain a result of the injury. The importance of attribution of pre-existing symptoms to the trauma has been emphasized in previous studies [35,71]. In line with this, a tendency to underestimate experienced symptoms such as back pain, neck pain and psychological distress experienced before the accident [72] has been found.

After a whiplash accident, neck pain might also lead to fear of serious damage and chronicity. This again leads to amplification $[26,40,73]$; neck pain will be more noticed and appear more troublesome.

Looking at this the other way around, individuals experiencing an increased load of somatic symptoms are more likely to spend time thinking about what causes their symptoms. These individuals are therefore more likely than others to remember and report all types of injuries and accidents, which for this purpose can be labeled the recall bias hypothesis. Exploring if somatic symptoms were equally increased in individuals selfreporting a past fracture of hand or wrist, we found at best limited support for this recall bias hypothesis. There was only a very modest increase in the overall somatic symptom score in individuals self-reporting fractures, and limited to only six symptoms.

A declining number of self-reported injuries was found with increasing time since accident. Alongside this, the association between a reported whiplash injury and somatic symptoms got slightly stronger. This finding is contrary to the organic model for chronic whiplash and coherent with several other explanations including the functional model, recall bias, and other explanations.

Anxiety, depression and benefit receipt were the covariates separately attenuating the association between chronic whiplash and somatic symptoms the most. The increased load of symptoms of anxiety and depression found among individuals reporting a whiplash injury, is in line with previous studies $[3,13,15,21]$. Two explanations have been given for the increased level of anxiety and depression seen in chronic whiplash: It has been considered a psychological response to the injury, like in post-traumatic stress disorder, or as a response to physical pain resulting from the injury [74]. Recent findings do, however, suggest reverse causality, namely that: anxiety and depression at baseline increases the risk of reporting whiplash at follow-up [35]. This debate of cause or effect in the association between whiplash and anxiety/depression does have consequences for whether anxiety/depression is to be regarded a mediating, confounding or even moderating factor in this association. However, our cross sectional design precludes further exploration of the temporal alignment of chronic whiplash and symptoms of anxiety/depression.

The increased symptom reporting, the broad symptom profile and the importance of amplification and attribution, indicate that chronic whiplash cannot merely be 
considered an organic disorder caused by a neck injury. In previous studies, also other aspects by chronic whiplash have been explored, supporting this.

First, there is a drastically varying prevalence of chronic whiplash in different cultures with similar traffic pattern [40]. Also, the outcome after a whiplash trauma is more affected by cultural expectations $[2,75]$ and cultural factors that generate symptom amplification and attribution [40], than by the actual speed, forces or tissue damage [2,18,76-78]. This is in accordance with the functional model for whiplash, but more difficult to incorporate in relation to the organic model.

Thoughts and emotions in relation to the accident are also of importance for prognosis [78,79]. For instance, the feeling of not being responsible for the accident, and being angry or worried, predict a worse outcome $[53,80,81]$. Pain-related fear and avoidance appear to be essential in developing chronic pain and disability [73,82]. Also, poor expectations for recovery are tightly associated with poor recovery $[83,84]$.

People experiencing whiplash accidents in relation to sports stand out from other whiplash victims with their absence of chronic symptoms and disability [27]. At the same time, even a placebo rear-end collision without biomechanical potential for injury might give rice to head and neck pain [85]. Finally, individuals self-reporting whiplash have increased risk of being awarded disability pension, also in the absence of neck-pain, and medico-legally for a whole range of diagnoses [35].

The debate over whiplash being a functional or organic disorder is by far settled by this study. But the broad symptom profile found among sufferers of chronic whiplash strongly resembles the diffuse and non-specific profile presented by individuals suffering from functional somatic syndromes [26,28,31,32], and our findings support the repeated suggestions that chronic whiplash is best understood and treated as a functional somatic syndrome [21,26,27].

One attempt to settle or calm the debate over whether chronic whiplash best is regarded an organic disorder or functional somatic syndrome is to introduce alternative perspectives and models. For example, chronic whiplash has been described with a biopsychosocial approach [40]. This alternative model dismisses both the organic and the functional model for whiplash, and suggests that chronic whiplash is a result of cultural expectations, and that symptom reattribution and amplification is of importance. At the same time the possibility of coexisting physical or psychological causes for symptoms is kept open. The biopsychosocial model is broader than the functional somatic model and therefore less readily testable. Though we in our study aimed to investigate the functional somatic syndrome model, our results are also in line with the biopsychosocial model.

\section{Clinical implications}

The debate between the organic and functional model for whiplash has strong clinical implications, but will obviously not be settled on the basis of this study alone. Standard treatment of acute whiplash has been providing the patient with information on injury mechanisms (according to the organic model), advice on suitable activities, recommendations to rest the neck the first weeks, instructions on postural correction, and information on comfort and prevention from excessive movement of the neck that soft collars can provide [86]. Now, studies have concluded that active treatment is more effective [4,86-88] - the patient should be encouraged to do neck exercises [86] and continue if possible to be physically active $[27,89]$. Clinicians emphasizing the functional somatic syndrome model will try to avoid chronic whiplash by discouraging the patient from assuming the sick-role [26,27], and by undercutting alarming expectations about clinical course [26,73].

\section{Conclusion}

Individuals reporting chronic whiplash also report increased levels of 17 symptoms - including somatic symptoms not readily related to a neck injury. Though an organic origin of these symptoms cannot be excluded in this study, we have difficulties explaining the findings according to the organic disorder model for chronic whiplash. In our opinion, our findings are more in line with the predictions according to the functional somatic model for chronic whiplash. Our findings are also coherent with other etiological models and explanations, including the biopsychosocial model.

\section{Competing interests}

The authors declare that they have no competing interests.

\section{Authors' contributions}

Authors SMM, JCS and AM designed the study, while HGW contributed further to the scope of the study. SMM conducted literature searches, and provided summaries of previous research. SMM conducted the statistical analysis under the supervision of JCS and AM. All of the authors contributed to the interpretation of the findings, and SMM wrote the first draft of the manuscript. All authors contributed to further refinement of the first draft and the revised manuscript. All authors read and approved the final manuscript.

\section{Acknowledgements}

The data collection was conducted as part of HUSK (the Hordaland Health Study '97-'99) in collaboration with the Norwegian National Health Screening Service. The first author received a summer research grant from Uni Rokkan Centre.

\section{Author details}

${ }^{1}$ Faculty of medicine and dentistry, University of Bergen (UoB), Bergen, Norway. 'Division of Mental Health, Department of Public Mental Health, Norwegian Institute of Public Health, Bergen, Norway. ${ }^{3}$ Research Unit on Mental Health Epidemiology, Department of Health Promotion and Development, Faculty of Psychology, UoB, Bergen, Norway. ${ }^{4}$ Division of Psychiatry, St Olav University Hospital, Norwegian University of Science and Technology, Trondheim, Norway. ${ }^{5}$ University of New South Wales, School of Psychiatry, Sydney, Australia. 
Received: 14 September 2011 Accepted: 14 August 2012

Published: 31 August 2012

\section{References}

1. Evans RW: Whiplash around the world. Headache 1995, 35(5):262-263.

2. Lovell ME, Galasko CSB: Whiplash disorders-a review. Injury 2002, 33(2):97-101.

3. Barrett $K$, et al: A comparison of symptoms experienced following minor head injury and acute neck strain (whiplash injury). Journal of Accident and Emergency Medicine 1995, 12:173-176.

4. Sterner Y, Gerdle B: Acute and chronic whiplash disorders - a review. Journal of rehabilitation medicine 2004, 36:193-210.

5. Barnsley L, Lord S, Bogduk N: Whiplash injury. Pain 1994, 58(3):283-307.

6. Pearce JMS: A critical appraisal of the chronic whiplash syndrome. $J$ Neurol Neurosurg Psychiatry 1999, 66(3):273-276.

7. Matsumoto M, et al: Prospective Ten-Year Follow-up Study Comparing Patients With Whiplash-Associated Disorders and Asymptomatic Subjects Using Magnetic Resonance Imaging. Spine 2010, 35(18):1684-1690.

8. Borchgrevink G, Smevik O, Haave I, Haraldseth O, Nordby A, Lereim I: MRI of cerebrum and cervical column within two days after whiplash neck sprain injury. Injury - International Journal of the care of the injured 1997, 26 (5-6):331-335.

9. Stovner $\amalg$ : The nosologic status of the whiplash syndrome: A critical review based on a methodological approach. Spine 1996 21(23):2735-2746.

10. Rebbeck T, et al: A prospective cohort study of health outcomes following whiplash associated disorders in an Australian population. Injury Prevention 2006, 12(2):93.

11. Borchgrevink GE, et al: National health insurance consumption and chronic symptoms following mild neck sprain injuries in car collisions. Scandinavian Journal of Social Medicine 1996, 24(4):264-271.

12. Mayou R, Tyndel S, Bryant B: Long-term outcome of motor vehicle accident injury. Psychosomatic medicine 1997, 59(6):578-584.

13. Wenzel $\mathrm{HG}$, et al: A population study of anxiety and depression among persons who report whiplash traumas. J Psychosom Res 2002, 53(3):831-835.

14. Lee J, Giles K, Drummond PD: Psychological disturbances and an exaggerated response to pain in patients with whiplash injuries. J Psychosom Res 1993, 37(2):105-110.

15. Berglund $A$, et al: The association between exposure to a rear-end collision and future health complaints. Journal of Clinical Epidemiology 2001, 54(8):851-856

16. Gargan M, Bannister G: Long-term prognosis of soft-tissue injuries of the neck. J Bone Joint Surg Br 1990, 72-B(5):901-903.

17. Squires B, Gargan MF, Bannister GC: Soft-tissue injuries of the cervical spine: 15-year follow-up. J Bone Joint Surg Br 1996, 78-B(6):955-957.

18. Miettinen T, et al: Whiplash injuries in Finland: A prospective 1-year follow-up study. Clin Exp Rheumatol 2002, 20:399-402.

19. Miettinen $T$, et al: Whiplash injuries in Finland: the situation 3 years later. European Spine Journal 2004, 13(5):415-418.

20. Ferrari $\mathrm{R}$, et al: A re-examination of the whiplash associated disorders (WAD) as a systemic illness. Ann Rheum Dis 2005, 64:1337-1342.

21. Wenzel H, Mykletun A, Nilsen T: Symptom profile of persons self-reporting whiplash: a Norwegian population-based study (HUNT 2). European Spine Journal 2009, 18(9):1363-1370.

22. Hincapie CA, et al: Whiplash Injury is More Than Neck Pain: A PopulationBased Study of Pain Localization After Traffic Injury. Journal of Occupational \& Environmental Medicine 2010, 52(4):434-440.

23. Bogduk N, Teasell R: Whiplash: The Evidence for an Organic Etiology. Arch Neurol 2000, 57(4):590-591.

24. Curatolo $M$, et al: The Role of Tissue Damage in Whiplash-Associated Disorders: Discussion Paper 1. Spine 2011, 36:S309-S315. doi:10.1097/ BRS.0b013e318238842a.

25. Sterling $M$, et al: Potential Processes Involved in the Initiation and Maintenance of Whiplash-Associated Disorders: Discussion Paper 3. Spine 2011, 36:S322-S329. doi:10.1097/BRS.0b013e318238853f.

26. Barsky AJ, Borus JF: Functional somatic syndromes. Ann Intern Med 1999, 130:910-921.

27. Berry H: Chronic Whiplash Syndrome as a Functional Disorder. Arch Neurol 2000, 57(4):592-594.
28. Wessely S, Nimnuan C, Sharpe M: Functional somatic syndromes: one or many? Lancet 1999, 354(9182):936-939.

29. Escobar Jl, et al: Whether medically unexplained or not, three or more concurrent somatic symptoms predict psychopathology and service use in community populations. J Psychosom Res 2010, 69(1):1-8.

30. Ihlebæk C, Eriksen H, Ursin H: Prevalence of subjective health complaints (SHC) in Norway. Scandinavian journal of public health 2002, 30(1):20-29.

31. Walker $\mathrm{E}$, et al: Psychosocial factors in fibromyalgia compared with rheumatoid arthritis: II. Sexual, physical, and emotional abuse and neglect. Psychosomatic medicine 1997, 59(6):572-577.

32. Walker EA, et al: Psychiatric-Illness and Irritable-Bowel-Syndrome - A Comparison with Inflammatory Bowel-Disease. Am J Psychiatry 1990, 147 (12):1656-1661.

33. World Health Organization: The ICD-10 Classification of Mental and Behavioural Disorders: Diagnostic Criteria for Research. Geneva: World Health Organization; 1993

34. De Gucht VFB, Heiser W: Job stress, personality, and psychological distress as determinants of soamtization and functional somatic syndromes in a population of nurses. Stress Heal 2003, 19:195-204.

35. Mykletun A, Glozier N, Wenzel HG, Overland S, Harvey SB, Wessely S, Hotopf M: Reverse causality in the association between whiplash and symptoms of anxiety and depression. The HUNT study. Spine 2011, 36(17):1380-1386

36. Kato K, Sullivan PF, Pedersen NL: Latent class analysis of functional somatic symptoms in a population-based sample of twins. J Psychosom Res 2010, 68(5):447-453.

37. Klokk M, Gotestam $K$, Mykletun A: Factors accounting for the association between anxiety and depression, and eczema: the Hordaland health study (HUSK). BMC Dermatol 2010, 10(1):3

38. Klokk $M$, et al: Somatization: the under-recognized factor in nonspecific eczema. The Hordaland Health Study (HUSK). Br J Dermatol 2011, 164(3):593-601.

39. Kato K, Evengård B SPF, Pedersen NL: A population-based twin study of functional somatic syndromes. Psychol Med 2009, 39:497-505.

40. Ferrari $\mathrm{R}$, Schrader $\mathrm{H}$ : The late whiplash syndrome: a biopsychosocial approach. J Neurol Neurosurg Psychiatry 2001, 70(6):722-726.

41. Ozegovic D, Carroll LJ, Cassidy JD: What Influences Positive Return to Work Expectation? Examining Associated Factors in a PopulationBased Cohort of Whiplash-Associated Disorders. Spine 2010, 35(15):E708-E713.

42. Zigmond AS, Snaith RP: The hospital anxiety and depression scale. Acta Psychiatr Scand 1983, 67(6):361-370.

43. Herrmann C: International experiences with the hospital anxiety and depression scale - A review of validation data and clinical results. J Psychosom Res 1997, 42(1):17-41

44. Bjelland I, et al: The validity of the Hospital Anxiety and Depression Scale. An updated literature review. J Psychosom Res 2002, 52:69-77.

45. Olsson I, Mykletun A, Dahl A: The Hospital Anxiety and Depression Rating Scale: a cross-sectional study of psychometrics and case finding abilities in general practice. BMC Psychiatry 2005, 5:46. p. 46.

46. Haug TT, Mykletun A, Dahl AA: The association between anxiety, depression, and somatic symptoms in a large population: The HUNT-II study. Psychosomatic medicine 2004, 66(6):845-851.

47. Harvey SHM: Physical activity and common mental disorders. The. Br J Psychiatry 2010, 197:357-364.

48. Skogen JCHSB, Henderson M, Stordal E, Mykletun A: Anxiety and depression among abstainers and low-level alcohol consumers. The Nord-Trøndelag Health Study. Addiction 2009, 104(4):1519-1529.

49. Sivertsen BØS, Glozier N, Bjorvatn B, Mæland JG, Mykletun A: The effect of OSAS on sick leave and work disability. Eur Respir J 2008, 32(6):1497-1503.

50. Prince $M$, et al: Practical Psychiatrical Epidemiology. New York: Oxford University Press Inc; 2003:208

51. StataCorp: Stata Statistical Software: Release 12. College Station, TX: Stata Corporation LP; 2011

52. Cassidy JD, et al: Effect of eliminating compensation for pain and suffering on the outcome of insurance claims for whiplash injury. N Engl J Med 2000, 342(16):1179-1186.

53. Mayou R, Bryant B: Psychiatry of whiplash neck injury. Br J Psychiatry 2002, 180(5):441-448.

54. Wenzel HG, et al: Pre-injury health-related factors in relation to selfreported whiplash: longitudinal data from the HUNT study, Norway. European spine journal 2012, 21:1528-1535. 
55. Rodriquez AA, Barr KP, Burns SP: Whiplash: Pathophysiology, diagnosis, treatment, and prognosis. Muscle Nerve 2004, 29(6):768-781.

56. Scholten-Peeters GGM, et al: Prognostic factors of whiplash-associated disorders: a systematic review of prospective cohort studies. Pain 2003, 104(1):303-322.

57. Harder S, Veilleux M, Suissa S: The effect of socio-demographic and crashrelated factors on the prognosis of whiplash. Journal of clinical epidemiology 1998, 51(5):377-384.

58. Carroll LJ, et al: Course and prognostic factors for neck pain in WhiplashAssociated Disorder (WAD), Results of the Bone and Joint Decade 20002010 Task Force on neck pain and its associated disorders. European spine journal. European spine journal 2008, 17:S83-S92.

59. Berglund $A$, et al: The association between exposure to a rear-end collision and future neck or shoulder pain: A cohort study. Journal of Clinical Epidemiology 2000, 53(11):1089-1094.

60. Krohne K, Ihlebaek C: Maintaining a balance: a focus group study on living and coping with chronic whiplash-associated disorder. BMC Musculoskelet Disord 2010, 11(1):158

61. Merrick D, Stalnacke B-M: Five years post whiplash injury: Symptoms and psychological factors in recovered versus non-recovered. BMC Research Notes 2010, 3(1):190.

62. Bogduk N: On Cervical Zygapophysial Joint Pain After Whiplash. Spine 2011, 36:S194-S199. doi:10.1097/BRS.0b013e3182387f1d

63. Lord SM, et al: Chronic cervical zygapophysial joint pain after whiplash: a placebo-controlled prevalence study. Spine 1996, 21(15):1737.

64. Vetti N, et al: Magnetic Resonance Imaging of the Alar and Transverse Ligaments in Acute Whiplash-Associated Disorders 1 and 2: A CrossSectional Controlled Study. Spine 2011, 36(6):E434.

65. Myran $\mathrm{R}$, et al: Clinical characteristics, pain and disability in relation to alar ligament MRI findings. Spine 2011, 36(13):E862-E867.

66. Matsumoto $M$, et al: Cross-sectional area of the posterior extensor muscles of the cervical spine in whiplash injury patients versus healthy volunteers-10 year follow-up MR study. Injury-International Journal of the Care of the Injured 2012, 43(6):912-916.

67. Dullerud R, Gjertsen $\varnothing$, Server A: Magnetic resonance imaging of ligaments and membranes in the craniocervical junction in whiplashassociated injury and in healthy control subjects. Acta Radiologica 2010, 51(2):207-212

68. McLean SA: The Potential Contribution of Stress Systems to the Transition to Chronic Whiplash-Associated Disorders. Spine 2011, 36:S226S232. doi:10.1097/BRS.0b013e3182387fb4.

69. Kindler LL, Bennett RM, Jones KD: Central sensitivity syndromes: mounting pathophysiologic evidence to link fibromyalgia with other common chronic pain disorders. Pain Management Nursing 2011, 12(1):15-24

70. van Wilgen CP, Keizer D: The sensitization model to explain how chronic pain exists without tissue damage. Pain management nursing: official journal of the American Society of Pain Management Nurses 2012, 13(1):60.

71. Schrader $\mathrm{H}$, et al: Natural evolution of late whiplash syndrome outside the medicolegal context. Lancet 1996, 347(9010):1207-1211.

72. Carragee EJ: Validity of self-reported history in patients with acute back or neck pain after motor vehicle accidents. Spine J 2008, 8(2):311-319.

73. Buitenhuis J, de Jong PJ: Fear Avoidance and IIIness Beliefs in PostTraumatic Neck Pain. Spine 2011, 36:S238-S243. doi:10.1097/ BRS.0b013e3182388400

74. Gargan $M$, et al: The behavioural response to whiplash injury. J Bone Joint Surg Br 1997, 79-B(4):523-526.

75. Aceves-Avila FJ, Ferrari R, Ramos-Remus C: New insights into culture driven disorders. Best Practice \& Research Clinical Rheumatology 2004 18(2):155-171.

76. Kamper SJ, et al: Course and prognostic factors of whiplash: A systematic review and meta-analysis. Pain 2008, 138(3):617-629.

77. Nederhand MJ, et al: Cervical muscle dysfunction in chronic whiplashassociated disorder grade 2: the relevance of the trauma. Spine 2002, 27(10):1056

78. Sterling M: Does Knowledge of Predictors of Recovery and Nonrecovery Assist Outcomes After Whiplash Injury? Spine 2011, 36:S257-S262. doi:10.1097/BRS.0b013e31823881bc.

79. Ferrari R: Predicting central sensitisation. Australian Family Physician 2010, 39(11):863-866.

80. Ferrari $R$, Russell $A$ : Why blame is a factor in recovery from whiplash injury. Medical hypotheses 2001, 56(3):372-375.
81. Sullivan MJL, et al: Catastrophizing and Perceived Injustice: Risk Factors for the Transition to Chronicity After Whiplash Injury. Spine 2011, 36:S244-S249. doi:10.1097/BRS.0b013e3182387fed.

82. Vlaeyen JWS, Linton SJ: Fear-avoidance and its consequences in chronic musculoskeletal pain: a state of the art. Pain 2000, 85(3):317-332.

83. Holm LW, Carrol LJ, Cassidy D, Skillgate E, Ahlbom A: Expectations for Recovery Important in the Prognosis of Whiplash injuries. PLoS Medicine 2008, 5(5):e105.

84. Carroll LJ: Beliefs and Expectations for Recovery, Coping, and Depression in Whiplash-Associated Disorders: Lessening the Transition to Chronicity. Spine 2011, 36:S250-S256. doi:10.1097/BRS.0b013e31823881a4.

85. Castro WHM, et al: No stress - no whiplash? Prevalence of "whiplash" symptoms following exposure to a placebo rear-end collision. International Journal of Legal Medicine 2001, 114(6):316-322.

86. Rosenfeld MRPT, Gunnarsson RMD, Borenstein PMD: Early Intervention in Whiplash-Associated Disorders: A Comparison of Two Treatment Protocols. Spine 2000, 25(14):1782-1787.

87. Peeters GGM, et al: The Efficacy of Conservative Treatment in Patients With Whiplash Injury: A Systematic Review of Clinical Trials. Spine 2001, 26(4):E64-E73.

88. Côté P, Soklaridis S: Does Early Management of Whiplash-Associated Disorders Assist or Impede Recovery? Spine 2011, 36:S275-S279. doi:10.1097/BRS.0b013e3182388d32.

89. Carette S: Whiplash Injury and Chronic Neck Pain. N Engl J Med 1994, 330 (15):1083-1084.

doi:10.1186/1471-244X-12-129

Cite this article as: Myrtveit et al: Somatic symptoms beyond those generally associated with a whiplash injury are increased in selfreported chronic whiplash. A population-based cross sectional study: the Hordaland Health Study (HUSK). BMC Psychiatry 2012 12:129.

\section{Submit your next manuscript to BioMed Central and take full advantage of:}

- Convenient online submission

- Thorough peer review

- No space constraints or color figure charges

- Immediate publication on acceptance

- Inclusion in PubMed, CAS, Scopus and Google Scholar

- Research which is freely available for redistribution 